\title{
EFFECT OF TEXTURE ON FATIGUE PROPERTIES OF AGE-HARDENED Al ALLOYS UNDER ULTRASONIC LOADING
}

\author{
HIRONORI MATSUSAKO \\ Department of Mechanical Engineering, Kagoshima University, Kagoshima, 890-0065, Japan \\ k2044430@kadai.jp \\ KOHJI KARIYA \\ Department of Mechanical System Engineering, Dai-ichi University, Kirishima, 899-4395, Japan \\ k-kariya@daiichi-koudai.ac.jp \\ NORIO KAWAGOISHI \\ Department of Mechanical Engineering, Kagoshima University, Kagoshima, 890-0065, Japan \\ hiro@mech.kagoshima-u.ac.jp \\ QINGYUAN WANG \\ Department of Civil Engineering, Sichuan University, Sichuan, China \\ wangqy@scu.edu.cn \\ MASAHIRO GOTO \\ Department of Mechanical Engineering, Oita University, Oita, 870-1197, Japan \\ masagoto@cc.oita-u.ac.jp
}

\begin{abstract}
Effects of texture and loading frequency on the fatigue crack growth behavior of an extruded and a drawn Al alloys of 2017-T4 were investigated under ultrasonic loading frequency $(20 \mathrm{kHz})$ in the relative humidity of $25 \%$ and $85 \%$, respectively. The extruded alloy has a marked texture of (111) orientation, but this specified orientation is not observed in the drawn alloy. Most of fatigue life was occupied by the growth life of small cracks in the both alloys regardless of humidity. In the low humidity, crack growth was retarded at about $0.3 \mathrm{~mm}$ in length in the both alloys. Although crack growth was accelerated by high humidity in the early growth process, there was no or little influence of humidity on the growth rate of cracks over about $0.3 \mathrm{~mm}$ in the both alloys. After the retardation of crack growth, fracture surfaces featured with many slip planes in the extruded alloy and many facets in the drawn one, respectively. The difference in growth mechanism between short cracks $(<0.3 \mathrm{~mm})$ and longer ones $(>0.3 \mathrm{~mm})$ was caused by the environment at crack tips due to high crack growth rate under ultrasonic loading, and that between the both alloys was related to the degree of texture.
\end{abstract}

Keywords: Ultrasonic fatigue; Age-hardened Al alloy; Extruded; Drawn; Fracture mechanism 


\section{Introduction}

Application of high strength Al alloys is very effective to reduce environment load, because the alloys have excellent properties like a high specific strength, easy to recycle and so on. However, the alloys have no definite fatigue limit. Therefore, it is important to know their fatigue properties in long life region. In order to save testing time, ultrasonic fatigue test is an attractive technology for the evaluation of fatigue properties in the long life region, which used to be a time consuming task under conventional test. However, the effect of high frequency on fatigue properties has not been fully understood. Especially, the effects of environment, microstructure and loading frequency on the properties are important factors to be clarified ${ }^{1,2}$.

In the present study, fatigue tests under ultrasonic loading frequency $(20 \mathrm{kHz})$ were carried out for two kinds of age-hardened $\mathrm{Al}$ alloys, an extruded and a drawn alloys of 2017-T4 (Al-Cu-Mg alloy) with nearly the same static strengths in $25 \%$ and $85 \%$, to investigate the effects of a texture and atmospheric moisture on the growth behavior of a crack under ultrasonic loading. In addition, rotating bending ones $(50 \mathrm{~Hz})$ were also carried out in nitrogen gas to examine the effect of water vapor and oxygen gas in ambient air at the crack tip.

\section{Material and Experimental Procedure}

Materials used were an extruded and a drawn bar of age-hardened Al alloy, 2017-T4. The chemical compositions (mass \%) of both alloys are shown in Table 1. Their mechanical properties are shown in Table 2.

Table 1. Chemical composition (mass\%).

\begin{tabular}{|c|c|c|c|c|c|c|c|c|}
\hline & $\mathrm{Si}$ & $\mathrm{Fe}$ & $\mathrm{Cu}$ & $\mathrm{Mn}$ & $\mathrm{Mg}$ & $\mathrm{Cr}$ & $\mathrm{Zn}$ & $\mathrm{Ti}$ \\
\hline Extruded Al alloy & 0.42 & 0.30 & 4.06 & 0.73 & 0.58 & 0.05 & 0.02 & 0.05 \\
\hline Drawn Al alloy & 0.41 & 0.32 & 3.87 & 0.70 & 0.62 & 0.04 & 0.03 & 0.04 \\
\hline
\end{tabular}

Table 2. Mechanical properties.

\begin{tabular}{|c|c|c|c|c|}
\hline & $\sigma_{0.2}(\mathrm{MPa})$ & $\sigma_{\mathrm{B}}(\mathrm{MPa})$ & $\sigma_{\mathrm{T}}(\mathrm{MPa})$ & $\Phi(\%)$ \\
\hline Extruded Al alloy & 350 & 471 & 638 & 32.4 \\
\hline Drawn Al alloy & 303 & 464 & 718 & 43.7 \\
\hline
\end{tabular}

Figure 1 shows inverse pole figure on the cross section of the bar. The extruded alloy has a marked texture on the (111) plane, but this specific orientation is not observed in the drawn one. This difference in texture may be related to the differed severities of work experienced during extruding and drawing, respectively. Therefore the obvious difference in both alloys is the degree of texture.

Figure 2 shows shape and dimensions of specimens. Prior to fatigue testing, all of the specimens were slightly electro-polished by $40 \mu \mathrm{m}$ to secure direct surface observation. The observation of fatigue damage and the measurement of crack lengths were conducted under a scanning electron microscope (SEM) or under an optical microscope by using the 
plastic-replica technique. Surface crack length, $\ell$, was measured in the circumferential direction of the specimen in the propagations of both tensile and shear modes. The crystallographic analysis was conducted by Electron Back Scatter Diffraction Pattern (EBSD) method. The fatigue tests were carried out using a $20 \mathrm{kHz}$ piezoelectricity actuated ultrasonic machine in the relative humidity $(\mathrm{RH})$ of $25 \%$ and $85 \%$. Some additional tests were carried out under rotating bending operated at $50 \mathrm{~Hz}$ repetition in nitrogen $\left(\mathrm{N}_{2}>99.995 \%, \mathrm{O}_{2}:<5 \mathrm{ppm}, \mathrm{H}_{2} \mathrm{O}<10 \mathrm{ppm}\right)$ gas to clear the effects of water vapor and oxygen gas included in ambient air. In ultrasonic fatigue, a pulse-pause test with times of $1 \mathrm{~s}$ and $5 \mathrm{~s}$ was carried out to reduce the temperature rise under high frequency. The humidity tested was selected by considering the daily humidity in use and the fact that the effect of humidity was significant above $60-70 \%{ }^{3}$. The deviation of humidity was $\mathrm{RH} \pm 5 \%$ and the temperature during tests was $25 \pm 5^{\circ} \mathrm{C}$ without control.

[001]

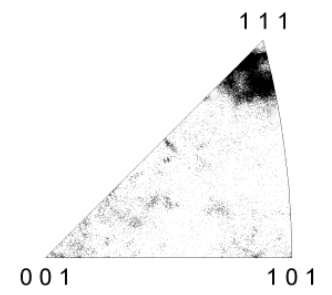

(a) Extruded Al alloy
[001]

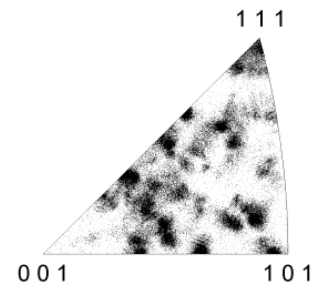

(b) Drawn Al alloy

Fig. 1. Inverse pole figure.

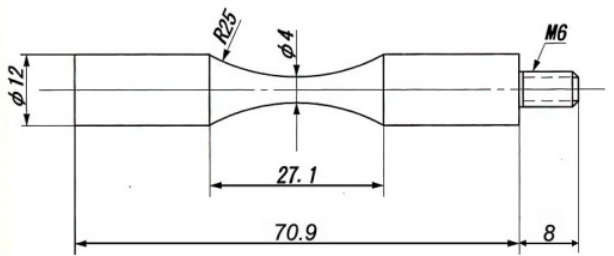

(a) Ultrasonic fatigue

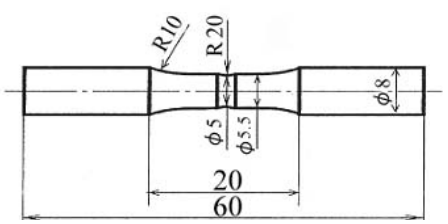

(b) Rotating bending fatigue

Fig.2. Shape and dimensions of specimens ( $\mathrm{mm})$.

\section{Experimental Results and Discussion}

Figure 3 shows crack growth curves of both alloys in humidity of $25 \%$ and $85 \%$. In Fig. 3 (b), the results in $25 \%$ are also indicated by lines only. Cracks initiated at the early stage of stress repetitions in both alloys, regardless of humidity. In the low humidity, a marked retardation of crack growth is confirmed at about $0.3 \mathrm{~mm}$ in crack length in both alloys. The crack growth rates before and after the retardation is higher in the extruded alloy than in the drawn one in the low humidity. On the other hand, the retardation of crack growth disappears in the extruded alloy and remains a little in the drawn one. Moreover, the crack growth rate before the retardation is accelerated by high humidity, while there 
is no or little influence of humidity on the crack growth rate after the retardation in each alloy.

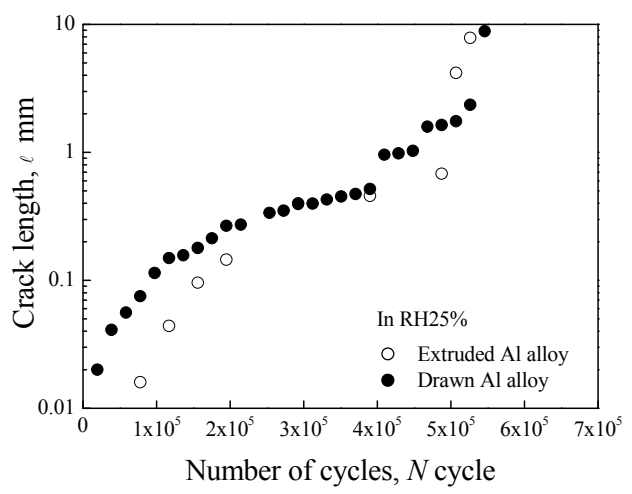

(a) In $25 \%$

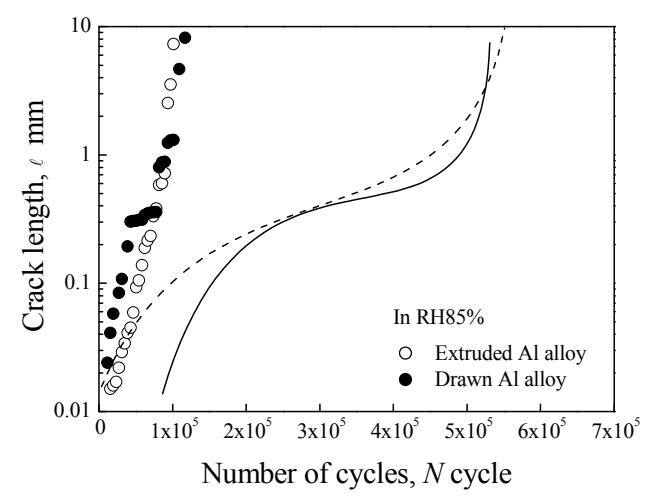

(b) In $85 \%$

Fig.3. Crack growth curves of extruded and drawn Al alloys $\left(\sigma_{\mathrm{a}}=230 \mathrm{MPa}\right)$.

Figure 4 shows crack morphologies of both alloys in the both humidity. A crack propagated macroscopically in a shear mode following the growth in a tensile mode in low humidity in the extruded alloy. Especially, in high humidity, most of crack growth is occupied by the growth of shear mode cracks. The direction of the shear mode cracks is about $35^{\circ}$ to the stress axis. On the other hand, the crack growth in the drawn alloy was in tensile mode during the whole propagation process, irrespective of the humidity.

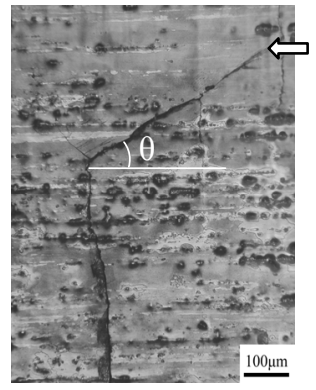

(a-1) In $25 \%$

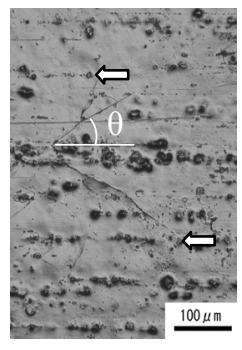

(a-2) In $85 \%$

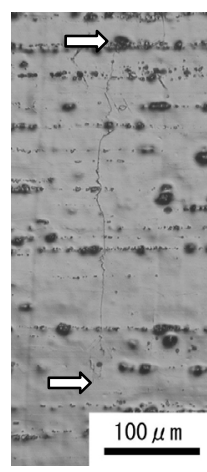

(b-1) In $25 \%$

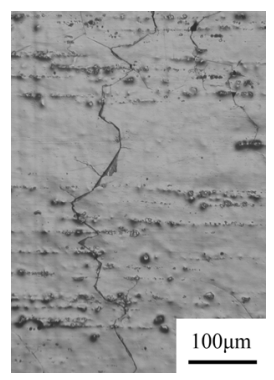

(b-2) In $85 \%$

(a) Extruded Al alloy

(b) Drawn Al alloy

Fig. 4. Crack morphologies ( $\Leftrightarrow$ axial direction, $\Leftarrow$ rack tip).

Figure 5 shows fracture surfaces in both alloys in the both humidity. Many slip planes are observed at the region where the shear mode crack propagated in the extruded alloy. On the other hand, many facets are observed on fracture surfaces yielded by the tensile 
mode cracks in the drawn alloy. However, few striation characteristic of typical growth of a fatigue crack, was observed on fracture surfaces in both alloys under rotating bending fatigue in air. By etch pit method ${ }^{4}$, it was confirmed that the fracture surface caused by the shear mode growth was (100) plane oriented. The angle formed between the (111) plane, which is the orientation of the alloys, and the (100) plane is nearly $55^{\circ}$, corresponding to the direction of the shear mode crack in the extruded alloy shown in Fig. 4. Therefore, the change in crack growth mode in the extruded alloy may be related to the marked texture of the alloy.

On the other hand, the difference in the growth mechanism of a fatigue crack after the retardation of a crack growth shown in Fig. 3 may be explained from the environment at the crack tip due to the high crack growth rate under ultrasonic frequency ${ }^{3,4-6 .}$ That is, the actual crack growth rate under ultrasonic loading is very high in comparison with that under the conventional loading frequency. Therefore, the environment at the crack tip may be close to the one in vacuum. In order to examine the above investigation, rotating bending fatigue tests were carried out in nitrogen gas where hardly contains oxygen and water vapor.

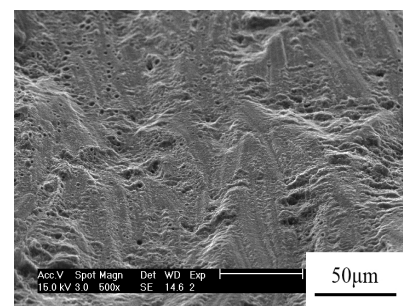

(a-1) In $25 \%$

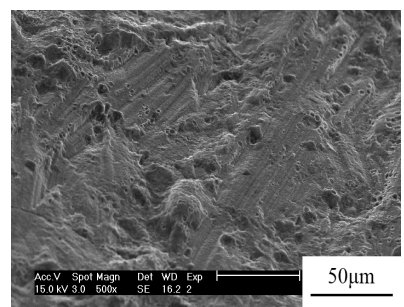

(a-2) In $85 \%$

(a) Extruded Al alloy

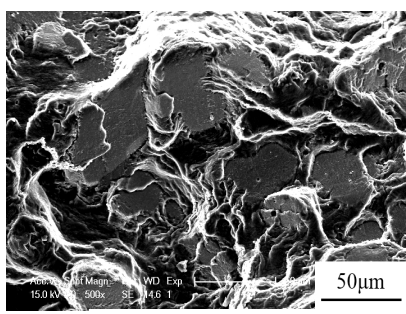

(b-1) In $25 \%$

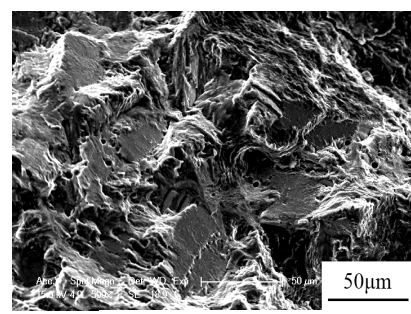

(b-2) In $85 \%$

(b) Drawn Al alloy

Fig. 5. Fracture surfaces.

Figure 6 shows fracture surfaces of both alloys tested under rotating bending in nitrogen gas. There are many sip planes in the extruded alloy and many facets in the drawn one, meaning that growth mechanism are nearly the same as the one under ultrasonic loading in both alloys. 


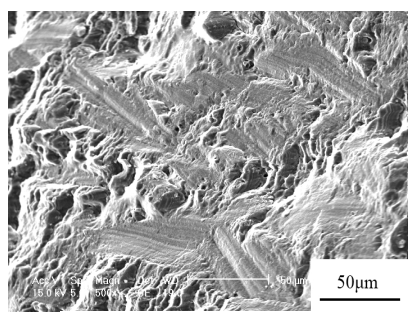

(a) Extruded Al alloy

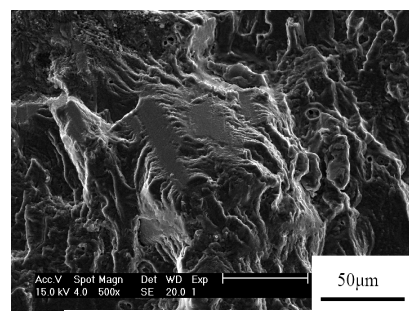

(b) Drawn Al alloy

Fig. 6. Fracture surfaces under rotating bending in nitrogen gas.

\section{Conclusions}

In the present study, fatigue tests under ultrasonic loading frequency $(20 \mathrm{kHz})$ and rotating bending $(50 \mathrm{~Hz})$ were carried out for two kinds of age-hardened Al alloys, the extruded and the drawn alloys of 2017-T4, to investigate the effects of a texture and loading frequency on the growth behavior of fatigue cracks. The cross section of the extruded Al alloy had a marked texture of (111) plane, but the drawn alloy had not any specified orientation. In low humidity, the growth of a crack retarded at about $0.3 \mathrm{~mm}$ in length in both alloys. Although the crack growth was accelerated in the early growth process by high humidity, there was no or little influence of humidity on the growth rate after the retardation of crack growth in both alloys. After the retardation of crack growth, fracture surfaces were covered with many slip planes in the extruded alloy, while many facets in the drawn one. These fracture surfaces under the ultrasonic loading are different from those under the conventional loading frequency. The difference in growth mechanism between short cracks $(<0.3 \mathrm{~mm})$ and longer ones $(>0.3 \mathrm{~mm})$ was caused by the environment at crack tips due to high crack growth rate under ultrasonic loading, and that between the both alloys was related to the degree of texture.

\section{References}

1. B. Holper et al. "Near Threshold Fatigue Crack Growth in Aluminum Alloys at Low and Ultrasonic Frequency: Influences of Specimen Thickness, Strain Rate, Slip Behavior and Air Humidity", International Journal of Fatigue, 25, 307 (2003).

2. E. Takeuchi et al. "Effect of Frequency on Giga-Cycle Fatigue Properties for Ti-6Al-4V Alloy", Transactions of the Japan Society of Mechanical Engineers, Series A, 70, 696, 1174 (2004).

3. N. Kawagoishi et al. "Fatigue Strength of Age-hardened \& Extruded Al Alloy under High Humidity (Rotating Bending and Ultrasonic Loading)", Transactions of the Japan Society of Mechanical Engineers, Series A, 76, 772, 1651 (2010).

4. R.M.N. Pelloux, "Mechanism of Formation of Ductile Fatigue Striations", Transaction of ASM, 62, 281 (1969).

5. N. Kawagoishi et al. "Propagation of Shear Mode Crack in Age-hardened and Extruded Al Alloy under Ultrasonic Loading", Transactions of the Japan Society of Mechanical Engineers, Series A, 76, 767, 938 (2010).

6. T. Fukudome et al. "Effect of Humidity on Fatigue Strength of Age-Hardened Al Alloy under Ultrasonic Loading", Transactions of the Japan Society of Mechanical Engineers, Series A, 76, 767, 947 (2010). 